\title{
ENTRE LA POESÍA Y LA ANÉCDOTA: LA GUARACHA CUBANA COMO TEXTO POPULAR ${ }^{1}$
}

\section{Ana CHOUCIÑO FERNÁNDEZ}

Universidade de Santiago de Compostela

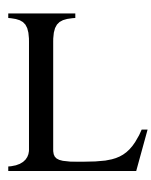

a canción constituye uno de los registros más frecuentes y eficaces para expresar todo tipo de experiencias humanas. Su eco y recepción es un indicador fiable de la idiosincrasia de una colectividad en un espacio o momento concretos. Por ello, la canción, y en particular la canción popular, se convierte en un corpus sumamente interesante para los estudios de la cultura ${ }^{2}$.

Actualmente llevo a cabo una recopilación de material diverso (artículos en libros, revistas o en red, antologías, diccionarios, grabaciones, letras en carátulas de discos) con el objeto de estudiar letras de guarachas cubanas, modalidad literario-musical que, salvo las menciones en historias o monográficos de la música cubana o algún artículo breve en revistas electrónicas, no ha sido objeto de atención académica. El trabajo que preparo constará de un ensayo en el que se examinará la guaracha como un género de dimensión popular y pública, además de incorporar una selección representativa de las letras de guarachas más destacadas. Lo que se presenta aquí es solamente un breve y discontinuo bosquejo de ideas con el que se intenta avanzar una respuesta crítica a la demanda teórica planteada desde el proyecto de investigación El discurso no lírico en la poesía contemporánea: espacios, sujetos, hibridación enunciativa, medialidad: «se hace urgente propiciar una indagación teórica del espacio realmente existente y con certeza consolidado de lo no lírico, cruzado por las plurales líneas en las que la proyección

\footnotetext{
${ }^{1}$ Trabajo vinculado con el proyecto de investigación El discurso no lírico en la poesía contemporánea: espacios, sujetos, hibridación enunciativa, medialidad, con financiación pública del Ministerio de Ciencia e Innovación (FFI2009-12746).

${ }^{2}$ Patricia Mohammed, que se ha ocupado de la canción popular del área caribeña apunta que: «The field of cultural studies and, within this, popular music in particular, offer the opportunity both to explore and to appreciate continuity and change (...) I think that song traditionally reflect the moods, ideas and feelings that people have about the things that concern them at any period» (Mohammed, 2002: 36-39).
} 
social y política del discurso poético cobra protagonismo en detrimento de una inscripción hacia lo privado en sus diferentes modalidades» (Casas, 2011: 6).

El género de la canción popular ofrece un marco que permite reflexionar sobre algunas de las cuestiones que se han asociado con el concepto de "poesía" y que han llevado a aplicar este término casi automáticamente a cualquier discurso centrado en la expresión subjetiva del yo. Durante mucho tiempo se ha hecho equivaler el término "poesía" a la idea que el romanticismo decimonónico extendió de poesía lírica. La canción popular, compuesta para ser interpretada con acompañamiento de instrumentos musicales, representa probablemente la quintaesencia de lo que se entiende generalmente por este género. No debe de ser casualidad el hecho de que en inglés se emplee precisamente el vocablo "lyrics" para referirse a la letra de una canción.

Sin embargo, cabe considerar que el discurso de la canción encierra muchas modalidades, además de la expresión de las emociones del yo; o, lo que es lo mismo, que la lírica no siempre ha de ser exclusivamente reflejo de un yo subjetivo. Los géneros no pueden ser categorías limitantes sino instrumentos teóricos flexibles que permitan una comprensión lo más nítida y minuciosa posible de las obras. Como sugiere Werner Wolf (2005), la poesía lírica puede ser entendida como una especie de macrogénero con un corpus muy heterogéneo cuyos textos comparten sólo dos atributos básicos incuestionables: el ser textos literarios y ficcionales. Wolf distingue nueve rasgos que pueden aparecer en un texto lírico sin que necesariamente todos ellos tengan que estar siempre presentes o ser relevantes en todos los casos. Son los siguientes:

1. Texto escrito para ser representado o cantado por la voz humana, es decir, una composición en la que la oralidad sea un rasgo destacado.

2. Brevedad (permite la memorización).

3. Desviación general del lenguaje corriente de uso común y de las convenciones discursivas.

4. Versificación. Presencia destacada de potencialidad acústica, patrones rítmicos y métricos, versificación visual, estructuración en estrofas.

5. Marcada autoreferencialidad y reflexión.

6. Existencia, como origen del texto, de una consciencia aparentemente no mediatizada, un yo lírico que produce el efecto de monologismo.

7. Importante perspectiva emocional. Énfasis en la percepción individual del sujeto.

8. Poca importancia o falta de acción externa o de un desarrollo narrativo a través de una cronología o de la causalidad. 
Entre la poesía y la anécdota: la guaracha cubana como texto popular

9. Ausencia de referencias a cualquier aspecto "real" del mundo, vaguedad, idea de lo absoluto ${ }^{3}$.

Teniendo en cuenta estas nueve características, las letras que se abordan en el presente trabajo registran únicamente tres, sólo un tercio del total. Se trata de composiciones para ser cantadas o representadas, breves y con estructura versal y estrófica. Pero se desmarcan del patrón descrito en la medida en que contienen evidentes referencias a la realidad; utilizan un lenguaje popular, cargado de expresiones coloquiales u ordinarias; dan entrada a la participación de un coro que sirve de contrapunto a la voz del intérprete; recogen, de forma indirecta, perspectivas ajenas a la del hablante, incorporando cierto grado de dialogismo y, en ocasiones, muestran también elementos indicativos de temporalidad y causalidad. Estamos, en fin, ante un género literario-musical de una pronunciada hibridez, a medio camino entre lo poético y la anécdota trivial.

Por tanto, para ilustrar este desvío del patrón general de la lírica, acudiré a una serie de versos de guarachas que, lejos de transmitir ideas de absoluto o emociones personales, constituyen una vuelta de lo poético a la calle, una llamada del compositor o intérprete -especie de juglar de cuño contemporáneo- para disfrute popular en el espacio público.

\section{Del teatro a la calle: historia de la guaracha}

Así pues, se abordará el desarrollo histórico de la canción guaracha desde sus orígenes hasta la época reciente. Para ello, se traerá a colación el traslado a América de las formas del teatro breve, ya que las guarachas tuvieron su origen precisamente en el teatro bufo del siglo XIX, en el que sustituyeron al entremés. Según Eduardo Robreño, «eran unos números musicales interpretados en los intermedios de las obras, y muchas veces dentro de ellas mismas» $(1961: 28)^{4}$.

La guaracha es un tipo de canción popular cubana. En el Diccionario Harvard de Música (1997) se puede encontrar la entrada que define esta variedad musical:

Una canción y un género de música danzada cubano, prominentes en los espectáculos teatrales del silgo XIX y un elemento importante de los repertorios de los conjuntos urbanos de danza popular en el siglo XX. La guaracha moderna destaca por sus textos pintorescos y a menudo satíricos. Está escrita en un compás binario moderadamente rápido, y al igual que otras formas de danzas populares cubanas, está integrada por varias secciones, con inclusión de pasajes instrumentales a solo y en grupo (eg. para metal y

\footnotetext{
${ }^{3}$ Mi traducción de "Absence of references to a specific slice of a known world, absolutness".

${ }^{4} \mathrm{El}$ examen del repertorio de guarachas del año 1882 permitirá extraer importantes conclusiones acerca del éxito del género en la Isla. Por otra parte, Margit Frenk (2002) ofrece información valiosa sobre las modalidades de la poesía americana en los inicios de la etapa colonial.
} 
teclado), versos para el solista vocal e intercambios pregunta-y-respuesta entre un solista que improvisa y el coro.

En 1946 Alejo Carpentier dio a conocer uno de los estudios más citados y todavía ensayo de referencia en el campo musical, La música en Cuba. El autor de El siglo de las luces señala la asociación de la guaracha con el baile y con el teatro bufo cubano y explica que, cantadas inicialmente en el teatro, en poco tiempo las guarachas se expandieron fuera de los escenarios:

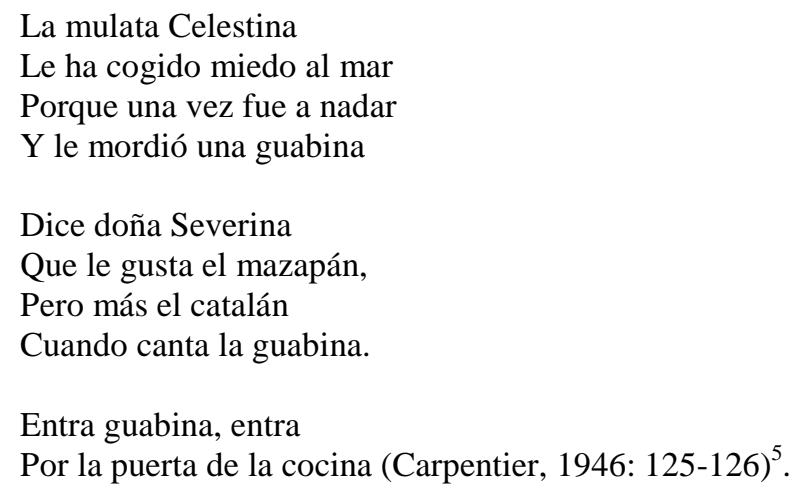

Hubo, pues, un momento en el que la guaracha se traslada del escenario a la calle, donde se vuelve un lenguaje compartido por autores, intérpretes y público. Por ello, es necesario seguir la evolución de la guaracha en el siglo XX teniendo en consideración circunstancias como su difusión a través de medios como la radio, la política discográfica, el éxito internacional de algunos autores y artistas o el triunfo de la Revolución. Se hará especial hincapié en los principales autores y en las composiciones más destacadas, algunas de las cuales marcaron época y fueron la expresión de un sentimiento colectivo, como en el caso de Miguelito Valdés y su "Son de la loma" o "La Habana no aguanta más", de Juan Formell.

Los temas más habitualmente tratados en estas composiciones son anécdotas de la realidad y la vida cotidiana: tipos, costumbres, la mujer (en particular, la mulata), las relaciones interraciales, los acontecimientos de vecindarios y barrios, modas chocantes o hechos con eco social son presentados con jocosidad e ingenio. Formalmente se imponen las estrofas breves interpretadas por una voz principal. Con ella interacciona un coro que repite el estribillo, estableciendo una suerte de discurso dialogado, casi siempre según el esquema de pregunta y respuesta: «El coro siempre era más o menos regular y la parte solista admitía la improvisación. Sobre todo cuando se trata de una fiesta de gentes del pueblo, en su propio ambiente, la improvisación se hacía más

\footnotetext{
${ }^{5}$ Carpentier recoge la letra de la que es probablemente una de las más antiguas manifestaciones de este género musical: la famosa "Guabina", que anoto por ser el punto de partida del estilo musical que aquí se considera.
} 
obligada, refiriéndose a cosas del momento» (León, 1964: 86). El fundamento de esta música se encuentra en el mestizaje entre lo africano y lo hispano, un fenómeno que alcanzó una de sus máximas expresiones en el Caribe:

La alternancia de coro y solista, haciendo éste cuartetas o pasajes variados es muy antigua en nuestra música [...] esta forma de cantar es universal, aparece en todos los pueblos y lo pueden haber traído los españoles, pero también es una forma de cantar muy característica en África. Es posible que en Cuba las dos vías se reunieran y dieran una gran fuerza a nuestro folklore (León, 1964: 87).

La canción guaracha cumplió, al igual que otras modalidades de la lírica popular, la función de crónica y recuento de historias, tanto de individuos como de colectividades. Sin embargo, no se ocupa de hechos heroicos o motivos graves, como hicieran los romances, sino que prefiere por lo general los asuntos cotidianos sin importancia. La guaracha hace crónica de las pequeñas anécdotas, siempre con humor -frecuentemente picante- y predilección por ciertos motivos recurrentes: los personajes y espacios populares. Así pues, será imprescindible tener en cuenta el carácter de creación popular ${ }^{6}$ del género guaracha, y considerar el importante papel que adquiere la dimensión pública y social del mismo.

El primero de los rasgos que distingue a los textos populares es la utilización poco ortodoxa del lenguaje. Los textos populares tienden a hacer un uso frecuente de figuras como el juego de palabras con doble sentido. Tanto el autor (productor) como el lector (consumidor) del texto popular encuentran satisfacción en el hecho de jugar con los diferentes significados de una palabra, que puede revelar características regionales, de clase o raza, e incluso adquirir más fuerza que los significados "oficiales". Los juegos de doble sentido invitan a lecturas "productivas" en las que el lector disfruta captando los múltiples significados que encierran, a veces incluso contradictorios:

$$
\begin{aligned}
& \text { Ofelia tenía un platito } \\
& \text { que era de lo más gracioso } \\
& \text { y a Rafael, el goloso, } \\
& \text { se lo prestó un momentito. } \\
& \text { ¿Y que pasó? } \\
& \text { ¡Que se rompió! } \\
& \text { Ofelia, no hay que contar } \\
& \text { el grito puso en el cielo, } \\
& \text { Y Pancho, cual caballero, } \\
& \text { se lo tuvo que pagar. } \\
& \text { ¡Le zumba el mango! (... })^{7}
\end{aligned}
$$

\footnotetext{
${ }^{6}$ En la caracterización del texto popular se sigue el análisis del libro Understanding Popular Culture, de John Fiske (1989).

${ }^{7}$ Fragmento de la guaracha "El plato roto", de Rafael Ortiz (1908-1994).
} 
Los juegos de palabras vulgares forman parte de la cultura oral, en claro contraste con la literatura culta, que prefiere una expresión seria y disciplinada. Puesto que el doble sentido es considerado trivial y frívolo, crea tensión entre el uso correcto y el empleo lúdico del lenguaje. Lo lúdico tiende a convertirse en motivo de indisciplina, escándalo y ofensa, razón por la que sufre el rechazo de la alta cultura y de los sectores hegemónicos en general. Los juegos de palabras son esencialmente orales (han de decirse en voz alta), desvían el lenguaje de la norma escrita y lo encaminan a los usos menos controlados, más contextuales de la cultura oral. No exige ortografía o sintaxis correctas, sus marcas distintivas son los errores, las desviaciones (sean deliberadas o no) de la disciplina de lo literario. El lenguaje oral se orienta más al contexto que a las normas.

Exceso, obviedad y abuso del cliché son otros de los rasgos propios de los textos populares. La cultura popular tiende a lo excesivo, razón por la que el sector académico la califica de superficial, obvia, demasiado simple. Pero esto no debe considerarse algo necesariamente negativo. El exceso conlleva elementos paródicos; y la parodia permite reírse de lo convencional:

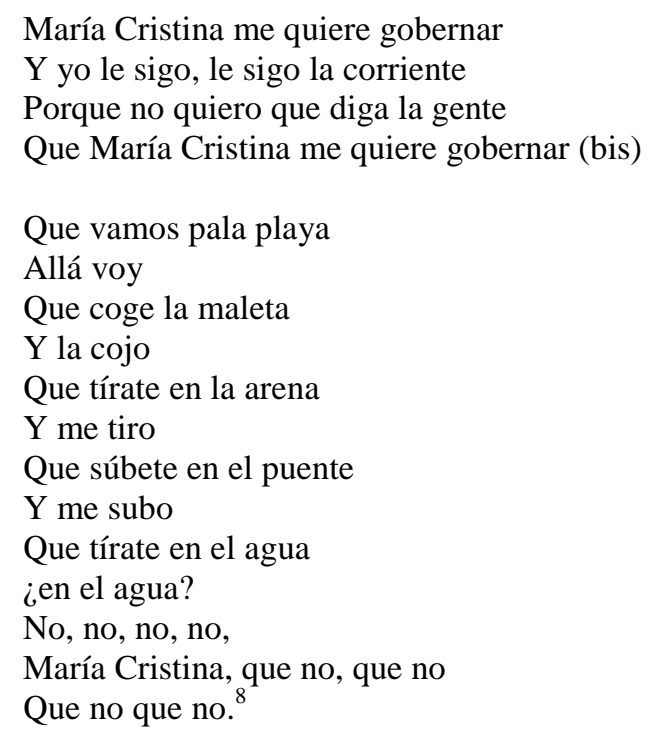

Las letras de guaracha están llenas de clichés que abarcan desde lo social a lo sexual: las modas, los oficios, el vividor, el negro y la mulata excesivamente sensuales; los alardes de actividad sexual, las argucias de las mujeres, los maridos engañados, los viejos lascivos, las vecinas chismosas $\mathrm{y}$, en general, cualquier motivo de humor de la vida diaria:

En una silla a mi lado,

Una joven se sentó,

\footnotetext{
${ }^{8}$ Fragmento de "María Cristina”, de Nico Saquito (1901-1982).
} 
Entre la poesía y la anécdota: la guaracha cubana como texto popular

\author{
Y en un punto delicado \\ Un alacrán le picó (Guarachas cubanas, 1882: 33). \\ Les diré lo que me trajo \\ A una mujer a espiar; \\ Que me caí boca abajo \\ En la calle de Escobar (Guarachas cubanas, 1882: 67). ${ }^{9}$
}

Por otra parte, si los clichés encierran máximas ideológicas, las guarachas, en especial las más antiguas, serían portadoras de la ideología propia del patriarcado blanco criollo, pues no en pocas ocasiones propagan tópicos sexistas, racistas e ideas prejuiciosas. El etnocentrismo, el chauvinismo, el rechazo de los grupos ajenos, los prejuicios, la intolerancia de las costumbres y estilos de vida de "los otros" constituyen una amplia base para el desarrollo del denominado "humor étnico". En general, los grupos raciales tienden a construir estereotipos al achacar a otras razas defectos de todo tipo como apetito exagerado, falta de higiene, desenfreno o sensualidad excesiva. Los estereotipos constituyen una base importante para esta modalidad de humor, porque ofrecen ideas preconcebidas y extendidas sobre los colectivos a los que va dirigido. La generalización desmedida es un rasgo característico del humor étnico: los grupos se ven como completamente homogéneos y se ignoran las variantes dentro de cada uno. Un efecto del humor racial, recurrente en las guarachas, es que suele crear un fuerte sentimiento ya sea de pertenencia ya sea de exclusión de un grupo étnico concreto. En tal sentido, el humor opera con cierta ambivalencia, ya que puede actuar como sistema aglutinante o excluyente en la construcción identitaria de colectivos.

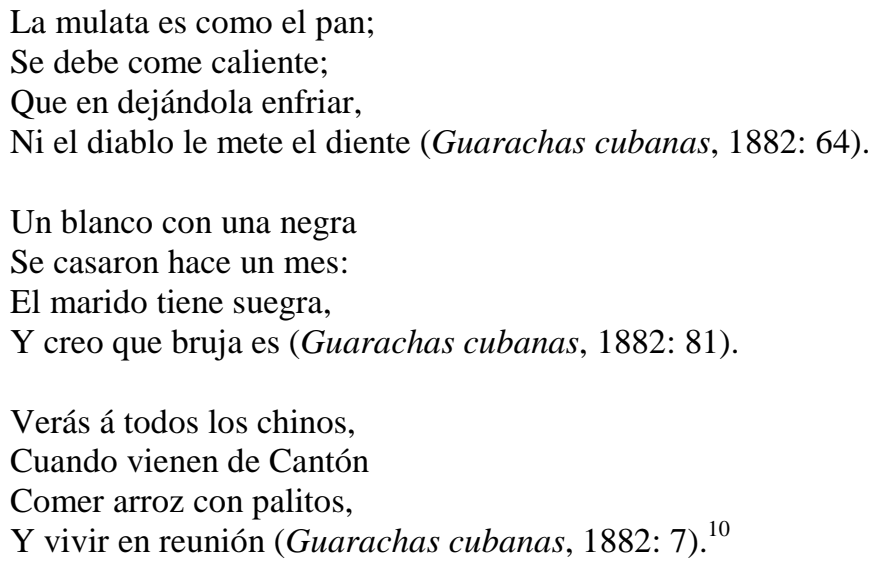

Los clichés niegan la singularidad del texto. Es por ello que son rechazados por el tipo de crítica que demanda del autor originalidad y creatividad. No obstante, los clichés e ideas que ponen en circulación las guarachas distan considerablemente de los

\footnotetext{
${ }^{9}$ Estrofas de las guarachas tituladas "El alacrán” y "El tropezón”, incluidas en el cancionero Guarachas Cubanas del año 1882 citado en la bibliografía final.

${ }^{10}$ Estrofas de las guarachas "La mulata", "Arroz con frijoles" y "Los chinos", respectivamente.
} 
empleados en otras creaciones populares como los seriales de radio y televisión protagonizados por heroínas idealizadas, residiendo la principal diferencia en el componente humorístico de las primeras.

A la literatura popular se le achaca una substancial escasez de elaboración. Con frecuencia se la califica de simplista y se la acusa de falta de sutileza y profundidad. Esto resulta muy evidente si es en el texto donde se busca la complejidad. Pero también es innegable que la complejidad de los textos populares reside más en sus usos que en las estructuras internas de los textos mismos. Si una letra de guaracha aborda asuntos triviales y está llena de lugares comunes, no es menos cierto que, dependiendo del momento y lugar en que se ejecute, así como del artista que la ponga en escena, las interpretaciones del mismo admiten muchas más posibles variantes y aperturas que en un texto culto, casi siempre terminado, cerrado. En este sentido, puede comprobarse que una misma guaracha adquiere distintos matices si se canta en un baile en la calle o en un teatro, si es o no un momento de crisis política, si la interpreta un hombre o una mujer, un blanco o un negro, un cantante joven o viejo, etc. Véase como ejemplo el texto que sigue:

\author{
Ten paciencia con abuelo; \\ recuerda bien cuanto hizo; \\ no contradigas su afán; \\ ponle atención a su juicio \\ gasta un poco de tu tiempo \\ complaciendo su egoísmo. \\ No olvide que abuelo \\ tiene un revólver y un cuchillo; \\ y mientras no se lo quiten \\ abuelo ofrece peligro.
}

Aunque sepas que no dile que sí; si lo contradices, peor para ti. ${ }^{11}$

Al contrario de lo que sucede con un texto culto, el autor del texto popular no es un elemento de gran importancia, siempre que la obra sea bien acogida por el público. Aunque siempre hay un letrista original, los textos populares llegan a ser composiciones colectivas, se adaptan a contextos, pero también a voces y estilos, de tal modo que es el intérprete antes que el autor el que adquiere más relevancia. Como han señalado con gran acierto Novo y Rábade (2008: 14):

[...] la noción de "autoría" en toda poesía popular es fluctuante y dispersa, advocada, como está, en la conjunción de voz y letra, a dar la impresión de "tradicionalidad", es decir, de oralidad de coautoría múltiple -hasta de anonimato patrimonio de todos. Todo ello valida, además, la transmisión de los textos-letra "con variantes" contextuales.

\footnotetext{
${ }^{11}$ Fragmento de la guaracha "Abuelo Paco", de Pedro Luis Ferrer (1952).
} 
De hecho, como fenómeno comunicativo, la guaracha presenta cierto grado de performatividad que depende en gran parte del intérprete (gestualización, instrumentación, vestuario llamativo). En otras palabras, la guaracha pone de manifiesto su vocación de discurso cantado y representado en el espacio público con intención lúdica:

\author{
La mujer de Antonio \\ Camina asi... \\ Cuando sale de la plaza \\ Camina asi... \\ Cuando trae la yuca \\ Camina asi... \\ La mujer de Antonio \\ Camina asi... ${ }^{12}$
}

Los instrumentos musicales con los que se acompaña la interpretación no son un detalle menor, ya que tanto el güiro como el tres o las maracas son elementos inconfundiblemente caribeños. Pero realmente es el vistoso vestuario lo más llamativo. Se trata de una indumentaria de origen teatral que llegó a internacionalizarse como vestuario típico de las agrupaciones musicales de $\mathrm{Cuba}^{13}$. Estos elementos propios de la guaracha contribuyen a reforzar el espíritu público, lúdico y carnavalesco de las canciones.

Es el público quien asimila y canta los textos populares cuando estima que la situación lo demanda, e incluso llega a hacerlos suyos, a modificarlos en alguno de sus versos según las circunstancias: «Popular texts are to be used, consumed, and discarded, for they function only as agents in the social circulation of meaning and pleasure» (Fiske, 1989: 123). Se trata de discursos que se reelaboran y se adaptan al contexto de la interpretación; versos enteros o elementos concretos circulan de una composición a otra, son inestables y "reciclables". Los textos populares se caracterizan por la pobreza textual y la intertextualidad:

The poverty of the individual text in popular culture is linked not only to its intertextual reading practices, but also to its ephemerality and repetitiousness [...] The poverty of the individual text in popular culture is linked not only to its intertextual reading practices, but also to its ephemerality and repetitiousness [...] popular culture is marked by repetition and seriality, which [...] enable it to fit easily with the routines of everyday life

\footnotetext{
${ }^{12}$ Fragmento de la guaracha "La mujer de Antonio" de Miguel Matamoros (1894-1871). Otro ejemplo es la guaracha titulada "El platanal de Bartolo" cuyo autor, Electo Rosell "Chepín” (1907-1984), es notablemente menos conocido que el intérprete que la popularizó, Ibrahim Ferrer (1927-2005).

13 «El vestuario de la guaracha tuvo un impacto tremendo en la industria del espectáculo en cuba (...). Los chalecos con volantes y mangas fruncidos así como las "colas" largas y ondeantes llegaron a asociarse con la rumba comercial durante ese período (años 1920 y principios de los 1930) al extremo de que sus orígenes en el teatro cómico fueron olvidados» (Robin Moore, 2002: 93).
} 
[...] popular culture is built on repetition, for no one text is sufficient, no test is a completed object. The culture consists only of meanings and pleasures in constant process [...] Distinctions among texts are as invalid as the distictions between text and life (Fiske, 1989: 125-126).

Las guarachas cubanas exhiben, en efecto, muchos elementos de intertextualidad, como se pone de manifiesto en varios ejemplos procedentes de la Curiosa recopilación de Guarachas Cubanas de 1882, cancionero en el que se reúnen títulos muy similares y repetitivos, participantes todos de un fondo común de tópicos y expresiones: "La mulata", "La mulata Rosa", "La mulata bailadora", "La Belén", "La Belencita":

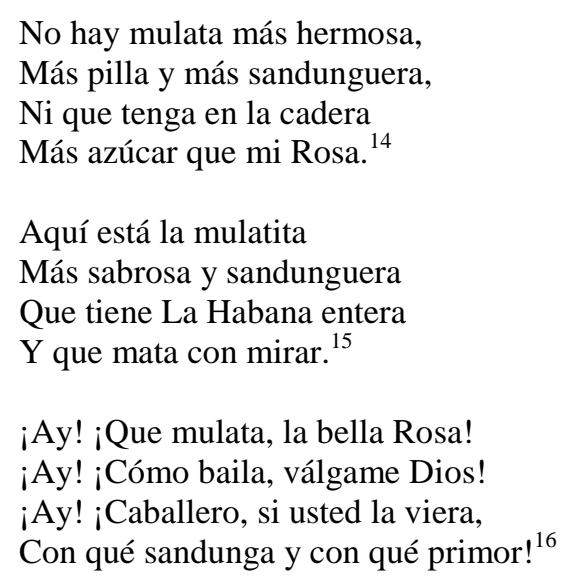

A todas las características anteriormente mencionadas de la guaracha como género popular hay que añadir otra, probablemente la más significativa: el humor. Durante largo tiempo los estudios literarios no han prestado a la cuestión del humor toda la atención que merece, por mucho que haya sido determinante en géneros como la comedia. Esta modalidad literaria, presente en la cultura occidental desde muy antiguo, se ocupa de temas que conciernen a grupos: al contrario de lo que sucede en la tragedia, donde tradicionalmente se tratan asuntos personales, que afectan a personajes muy individualizados, en la comedia los personajes son prototipos, no individuos, y opone a la anterior el optimismo y la sensación de liberación o catexis, lo que encaja con el carácter colectivo y público de los géneros populares como la guaracha.

Los musicólogos han asociado la guaracha con el choteo, la modalidad particular del humor caribeño: «Este estilo de canción con ritmo rápido, siempre recogió el choteo criollo, el hecho político o el tipo del pueblo, que se descreía de forma picaresca» (Linares, 1974: 36). Aun cuando el célebre estudio de Jorge Mañach, Indagación del choteo, publicado en 1942, está ya más que superado en muchas de sus afirmaciones

\footnotetext{
14 "La mulata Rosa" de Santiago Zamora.

15 "La Belencita", de L. G. Muchas de las guarachas del repertorio de 1882 aparecen firmadas únicamente con iniciales.

16 "La mulata bailadora", de J. T.
} 
deterministas, no deja de ser un referente esclarecedor entre los ensayos en torno a la psicología social del cubano y muy a propósito del género guaracha. Explicaría, por ejemplo, la preferencia de estas composiciones por la anécdota. Mañach alude a la "reivindicación de lo menudo" como característica del humor cubano:

Esta misma época nuestra, arisca a toda gravedad, insiste en reivindicar la importancia de las cosas tenidas por deleznables o ridículas, y se afana en descubrir el significado de lo insignificante [...]. El choteo - cosa familiar, menuda y festiva- es una forma de relación que consideramos típicamente nuestra [...]. Se ha tendido a desconocer la peculiaridad del fenómeno y a identificarlo con cualidades más genéricas del carácter criollo, como la "ligereza", la "alegría" y tales (Mañach, 1940: 10-12).

El choteo es, entre los cubanos, una costumbre arraigada que Mañach atribuyó al rechazo que este pueblo siente hacia cualquier tipo de autoridad, escalafón u orden:

Un hábito de irrespetuosidad -motivado por un mismo hecho psicológico: una repugnancia de toda autoridad [...]. El choteo es enemigo del orden en todas sus manifestaciones comporta una negación de la jerarquía, que para ciertos tipos de idiosincrasia tropical es siempre odiosa (Mañach, 1940: 19 y 33).

Por otro lado, no puede sorprender que las cosas o situaciones objeto de choteo coincidan precisamente con la mayor parte de los motivos que dan pie a las guarachas:

Lo "choteado" es, en cambio, aquello que tiene una reputación precaria o falsa: lo desprestigiado... La virtud de una mujer, el empeño intelectual de un hombre, la emoción de un funeral o de un duelo, se le convierten en materia de chacota [...] ¿No será el choteo en esa forma desvalorada, un dictado del resentimiento? [...] Sin duda en no pocos casos el choteo obedece a ese propósito de desahogo (Mañach, 1940: 36-37).

Estamos ante una postura ideológica llevada a la esfera pública. El choteo y su correspondiente musical, la guaracha, han servido de alivio colectivo a la ciudadanía cubana en momentos de crisis y dificultades, así como de socarrona crítica a comprometidas situaciones políticas en los momentos adversos, que no han faltado a lo largo de su historia.

Al par que uno de los grandes padecimientos del cubano, la burla crónica ha sido una de sus grandes defensas. Le ha servido de amortiguador para los choques de la adversidad; de muelle para resistir las presiones políticas demasiado gravosas y de válvula de escape para todo género de impaciencias. En otras palabras, ha sido entre nosotros un descongestionador eficacísimo (Mañach, 1940: 65-66).

El humor es también un medio de integración social en la medida en que favorece el establecimiento de una identidad y un sentimiento solidario con el colectivo. En suma, un aspecto importante del humor es que permite expresar abiertamente lo que de ordinario sería imposible: desafía o destruye las figuras de autoridad, al tiempo que se constituye en un instrumento de afirmación de los valores propios e ideas políticas 
personales, permite salir airoso de situaciones comprometidas o vergonzosas, abordar materias tabú como el sexo, liberarse del miedo y la tensión. La lista de los usos del humor es extensa, aunque no siempre funciona del mismo modo en todos los colectivos y situaciones.

El examen de las letras de canciones populares representa un desafío para el crítico literario porque, en general, éstas no responden a las mismas características de los textos de la alta literatura. Como sucediera en su día con la épica, ciertas letras de canción pueden considerarse creaciones poéticas singulares, destinadas al canto y a la representación antes que a la lectura individual en silencio. El análisis de estas letras corrobora lo que se apuntaba al comienzo del estudio: el concepto de poesía lírica, lastrado largo tiempo por las teorías románticas que lo asociaban exclusivamente a la expresión íntima y subjetiva del yo poético, resulta restringido en exceso cuando se consideran textos como los de las guarachas, composiciones de clara vocación pública y colectiva, en las que, además de la brevedad, la rima y su potencial oral y performativo, tienen también cabida lo anecdótico, la realidad externa, trazos de temporalidad y causalidad, lenguaje corriente o cierto grado de dialogismo. Cabe, por tanto, estudiar este conjunto de textos como género híbrido entre la poesía y la anécdota.

\section{Referencias bibliográficas}

BAKHTIN, M. (1989): La cultura popular en la Edad Media y en el Renacimiento. El Contexto de François Rabelais. Madrid, Alianza.

CASAS, A. (2011): "La poesía no lírica: enunciación y discursividad poéticas en el nuevo espacio público", en Actas del I Congreso Internacional de la Asociación Española de Teoría de la Literatura. Granada, Universidad de Granada, en prensa.

CARPENTIER, A. (1946): La Música en Cuba. La Habana, Editorial Letras Cubanas, $3^{\mathrm{a}}$ ed., 1988

RANDEL, D., ed. (1997): Diccionario Harvard de música. Versión española de L. C. Gago. Madrid, Alianza.

ÉVORA, T. (2003): Música cubana. Los últimos 50 años. Madrid, Alianza.

FISKE, J. (1989): Understanding Popular Culture. Londres y Nueva York, Routledge.

FRENK, M. (2002): "Poesía y música en el primer siglo de la colonia", en M. MASERA, coord., La otra Nueva España. La palabra marginada en la Colonia. México y Barcelona, Universidad Nacional Autónoma de México y Azul Editorial, pp. 17-39.

GUARACHAS CUBANAS. CURIOSA RECOPILACIÓN DESDE LAS MÁS ANTIGUAS HASTA LAS MÁS MODERNAS (1882): La Habana, Librería La Principal, Editora. Segunda edición corregida y aumentada. 
LEÓN, A. (1964): Música folklórica cubana. La Habana, Ediciones del Departamento de Música de la Biblioteca Nacional José Martí.

LINARES, M. T. (1974): La música y el pueblo. La Habana, Pueblo y Educación.

MAÑACH, J. (1940): Indagación del choteo. La Habana, La Verónica.

MOHAMMED, P. (2002): "Refining Gender Methodology: Studying Masculinity Through Popular Song Lyrics", en R. L. RAMÍREZ et al. eds., Caribean Masculinities Working Papers. San Juan, University of Puerto Rico, pp. 33-55.

MOORE, R. (2002): Música y mestizaje. Revolución artística y cambio social en La Habana. 1920-1940. Madrid, Colibrí.

NOVO VILLAVERDE, Y. - RÁBADE VILLAR, M. C. (2008): Te seguirá mi canción del alma... El bolero cubano en la voz de las mujeres. Santiago de Compostela, Universidade de Santiago de Compostela.

ROBREÑO, E. (1961): Historia del teatro popular cubano. La Habana, Oficina del Historiador de la Ciudad.

WOLF, W. (2005): “The Lyric: Problems of Definition and a Proposal for Reconceptualisation”, en E. MÜLLER- ZETTELMANN - M. RUBIK eds., Theory into Poetry. New Approaches to the Lyric. Rodopi: Ámsterdam y Nueva York, pp. 21-56. 